\title{
Optimization of Production process in Sewing Work for Ethiopia Cultural Clothe Apparel Production
}

\author{
Solomon Tilahun \\ Ethiopian Institute of Textile and Fashion Technology \\ Bahir Dar University \\ Bahir Dar, Ethiopia
}

\begin{abstract}
Purpose: - In the domestic production of garments, the more time is wasted for the handling of fabric. To reduce this wastage in garment production of sewing work aids required. These work aids are not only used to reduce the handling time but also used to improve the quality of the garments. The extent of process control in maintaining the processing parameters at the desired level can be reduced thereby maintaining quality \& increasing productivity.

Design/Methodology/Approach:-the researcher used types of machines used for each process, working hours of the garments, time taken and daily production of cultural dress style was enlisted and recorded as well. Those data were collected while the garments were manufactured without using work aids and appropriate work aids were developed and also when those same garments were manufactured in the sewing line with using sewing work aids in small scale enterprises.

Findings: - Folders for dressmakers is a vital tool of any garment manufacturing special in the sewing section. Sewing work aid mostly affects the production rate and quality of clothes that perceive customers. The cultural clothe makers have no how the sewing work aid use in the garment making.

Originality: This work and that all contributions from any other persons or sources are properly and duly cited. I further declare that the material has not been submitted either in whole or in part and the research identifies the bottleneck and proposes the solution. Small Scale Enterprises should improve in terms of quantity and quality to maintain in the market (competitiveness') and sustain the growth in order to change their status to a medium level that the Enterprise use different productivity improvement techniques such as the utilization of manpower, effective use of machines by use of some kinds of time-saving devices that facilitate operators to perform their work effectively with less effort and short time.
\end{abstract}

Keywords: Habasha Kamiss, Sewing Work Aid, Productivity.

\section{INTRODUCTION}

Ethiopia is one of the fastest developing economies in the world. Small enterprise is major players in the economic resurgence. They are instrument of change and vehicles of growth and diversification. ${ }^{[1]}$ The role of Micro and Small Enterprises (MSEs) in employment and income generation is increasingly recognized for the unemployed people, especially for women, and has become a major playing field for policymakers and donors with dual objectives of enhancing growth and alleviating poverty. ${ }^{[2]}$

Small and Medium-sized enterprises (SMEs) are a very heterogeneous group of businesses usually operating in the service, trade, agri-business, and manufacturing sectors. They include a wide variety of firms such as village handicraft makers, small machine shops, garment making and computer software firms that possess a wide range of sophistication and skills. Some are dynamic, innovative, and growth-oriented while others are satisfied to remain small and perhaps family owned. Small enterprises usually operate in the formal sector of the economy and employ mainly wage-earning workers. Small enterprises are often classified by the number of employees and/or by the value of their assets. For Ethiopia, the classification of enterprises into small, medium and 
large scale depends on a number of variables such as level of employment, turnover, capital investment, production capacity, level of technology and subsector shown below table 1 .

Table 1; Company Size Classification Structure for Ethiopia

\begin{tabular}{|l|l|l|l|l|}
\hline \multirow{2}{*}{ Sub-sector } & \multicolumn{3}{|c|}{ Number of employees } & \multirow{2}{*}{ Remark } \\
\cline { 2 - 4 } & Small scale & Medium & Large & $\begin{array}{l}\text { According to the Central Statistics Agency } \\
\text { (CSA) }\end{array}$ \\
\hline \multirow{3}{*}{ Textile and Apparel } & $5-9$ & $10-49$ & above 51 & $\begin{array}{l}\text { According to Federal Medium and Small } \\
\text { Enterprise Development Agency } \\
\text { (FeMSEDA) }\end{array}$ \\
\hline Leather & $2-10$ & $21-50$ & above 51 & \\
\hline Diary & $2-10$ & $21-50$ & above 51 & above 51 \\
\hline Wheat & $2-10$ & $21-50$ & above 51 & \\
\hline Wood Processing & $2-10$ & $21-50$ & &
\end{tabular}

Source: Ethiopia CSA and FeMSEDA

The Small and Medium Scale Enterprises are playing very significant role in almost all the economies around the world in irrespective of the country's development stage. However it is obvious that SSEs function as a lifeline in informal sector in under developed countries due to their contribution to overall economy in many aspects such as employment generation, exports, tax income, innovation, competitiveness, equitable income distribution, social stability, domestic resources usage, regional development and ultimately it is the main source of economic growth. ${ }^{[3]}$ The fast-changing economic conditions such as global competition, declining profit margins, customer demands for high quality products, product variety and reduced leadtime etc. have a major impact on manufacturing industries. The demand for higher value at lower price is increasing and to survive, apparel manufacturers need to improve their operations through producing right first-time quality and waste reduction. Reduction of waste can improve productivity; improving quality at the source will not affect any station, but reduces scrap and rework. Manufacturing defect less product will help to meet the demand. The sewing section in a garment firm is a most problematic section as compared with other value chains. Most of the time, failure happened in sewing section to meet delivery time because of Sewing operations (with respect to cutting and finishing) demands high skill in machine handling as well as material handling and more chances of producing defective products. So have to give more attention to stitching tasks than fabric cutting and other value chains of garment production. Firstly, in traditional type of unit production or individual production is the major problem faced by enterprise. Flexibility towards the style change over cannot be achieved easily with quantity and quality; which is the current demand (Decreasing order size and increasing number of style) of retail enterprise. To meet this requirement, during production should be designed in such a way that it should hold minimum work in process and should be flexible enough to the changing need of order.

\subsection{Products produced in small scale enterprise}

Ethiopia, with its vast diversity of ethnic groups, cannot claim to have just one type of cultural or traditional clothing. Some groups opt to wear nothing to very little, for example, the Hamer people traditionally wear goat skins and the Afar people's cultural dress is a waistcloth. The most widely spoken and written about piece of traditional clothing belonging to Ethiopia would have to be the "Habesha Kamiss/Kemise" or the "dress of the Habasha". It is usually produced as white, gray, or beige chiffon woman's dress that often falls to the ankles and is worn with a shawl. This is the culturally traditional clothing of the Habesha peoples and it usually has beautifully embroidered borders.

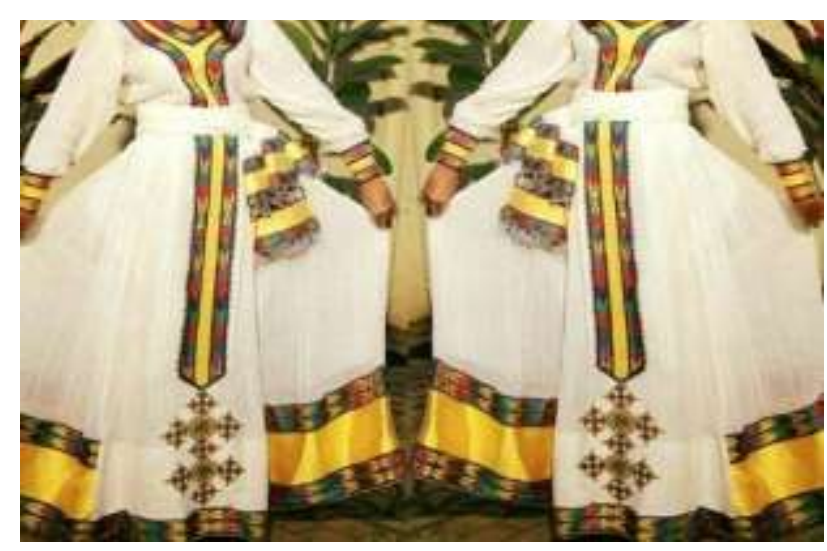

Figure 1 Ethiopian Traditional wear 


\subsection{Garment Manufacturing}

Garment manufacturing includes number of processes from order receiving to dispatching shipment of the finished garments. A process flow chart helps to understand how raw materials are moved from one process to another process until raw materials are transformed into the desired product (garments).Based on present apparel industry, garment manufacturing processes are categorized under Pre-Production Processes - Pre-production process includes sampling, sourcing of raw materials, Approvals, production planning meeting etc., Production processes - Production processes are cutting, sewing etc. And Post production processes - thread trimming, pressing, checking, folding and packing, shipment inspection etc.

A sewing machine is an important part of apparel and garments manufacturing technology. Production of garments factory depends on the performance of sewing machine and principles of stitching. Principles of stitching and perfection of stitching depends on the quality of sewing machine.

Mechanization is the process of replacing human labor with machines. Mechanization of the garments sewing process encouraged mass production of apparel garments product. Garments sewing that had long been performed by hand sewing machine could be done more rapidly by garments sewing machine. By about 1900, most garments sewing processes could be performed by machine.

Automation is a state of operating without external influence or control. In manufacturing of garments and apparels it is often viewed as highly desirable because it eliminates the potential for garments workers error. Automated garments sewing systems are capable of feeding themselves cut garments parts from a stack, completing multiple sewing tasks, and delivering finished parts of garments. Automated equipment for garments sewing may be cost effective for some apparel manufacturers, while the high costs of acquisition, installation, and maintenance are prohibitive to others.

The sewing section in a garment firm is a most problematic section as compared with other value chains. Most of the time, failure happened in sewing section to meet delivery time because of Sewing operations (with respect to cutting and finishing) demands high skill in machine handling as well as material handling and more chances of producing defective products. So have to give more attention to stitching tasks than fabric cutting and other value chains of garment production.

Firstly, in traditional type of unit production or individual production is the major problem faced by enterprise. Flexibility towards the style change over cannot be achieved easily with quantity and quality; which is the current demand (Decreasing order size and increasing number of style) of retail enterprise. To meet this requirement, during production should be designed in such a way that it should hold minimum work in process and should be flexible enough to the changing need of order.

Secondly, in batch process, since the operators are given specific jobs, they know one or few more operations only. Though he /she may have good skill and can work more efficiently on one (allocated job only) operation; he /she cannot work immediately on some other operation. This is another need of today's industry, because the fashion is changing frequently and the work force should be capable enough to cope with this change. To achieve this operator should be multi-skilled or using work aids which can be served by regular training and converting long assembly lines into small manufacturing cells.

Workload fluctuation and process balancing among operators is another problem in batch processing, because one operator is given one operation at a time. So the operator who is performing easier and low time consuming jobs can pile up a huge amount of work in process whereas in the critical operations (operations which need more time and skill) there is lagging which causes unbalanced work in process between machines and the work load.

\subsection{Definition Sewing machine Work aids}

Any addition made to a basic sewing machine with the objective of making the work easier is generally called as work aids. They are also called as deskilling devices, as without these devices for executing the same operation higher level of skill will be required. Typically, a sewing operation is of short cycle in nature. The basic work content might vary anywhere from few seconds to 2 minutes. All these cycles have six stages. They are: Pickup, Orientate, Match Sew, Trim and Dispose. The most commonly used work aids are those used for guiding or folding the fabric, trimming treads or other components and for stacking the work after sewing The least common are those which assist is the initial picking up of the parts to be sewn. ${ }^{[4]}$

\subsection{Need of work aids}

The additional can be made to basic sewing are many and they come under the general term work aids. The typical sewing operation has been analysed into stages of separate and pick up, orientate, mate, control through sewing and dispose. The term handling is normally used to describe those elements that are not sewing and it is this handling, along with that of dealing with garment bundles where they exist, plus various aspects of machine attention and personal needs, that make up 80 percent of the 
time spent working by most sewing machinists. In the search for improvements in the ratio of time spent sewing to time spent handling, some elements of the sewing operation offer more scope than others. Thus the nature of clothing materials makes the stage of separate and pick up difficult because the materials are limp and they slip or cling. In this case, what is difficult for machinist is also difficult to machines. Orientate and controls through sewing are slowed greatly in some operations because of the need to pause repeatedly to realign the parts or to fold them into position. Disposal may include severing the sewing thread as well as stacking the garment part. Sometimes the threads must be cut close for neatness while on other occasions a stitch type requires an end to be left. The stacking of completed parts by one operator not only takes time but may affect the next operator as well. Slowness, however, is not the only problem. While machinists are matching up fabric edges in order to sew them together to the correct width or turning up double rolled hems, not only are they working slowly but they are also trying to achieve the required quality standard in their work. Depending on the standards required in the relation to the operators skill levels and the nature of the fabric and the sewing operation, this will in some cases be very difficult. Achieving accurately controlled stitching at speed with operators without a high level of skill is greatly desired. A further drive for economy arises from the fact that there are some seam constructions where the final effect can be achieved in more than one way, typically in several stages of sewing with perhaps some pressing in between, or in just one stages by using a device that fold the fabric, along with a multi needle machine. Finally, in this justification of machinery development, machinists are required to change the operation that they do from time to time, and it is in the interests of efficiency in production that they are quickly able to gain proficiency in the new operation. Thus machinery is needed which will minimize the training time required on the new operation but without that machinery being too restricted in its flexibility. The operator did not worry about concentrating both on the needle point and the seam edge. This enables him to concentrate solely on stitching which increases the speed of sewing. A constant seam allowance is obtained and quality is improved. In case of over lock machines, the edge guide does not allow the operator to trim more than required. This helps maintain the correct size. Edge guides are of two types. Straight: This is used only when the seam line is straight. Curved: This has the shaped curve allowing the operator to move the aligned curved seam continuously, without stopping for realigning of seam.

\subsection{Types of work aids}

The work aids that are used during operations can be categorized in a number of different ways and vary in the aspects of their overall purpose that they emphasis. Some offer greatly increased speed of working in a situation where quality already satisfactory. Others give very little improvement in productivity but great accuracy of sewing. In terms of their function the commonest ones are used for guiding or folding materials, for trimming threads and other components from garments, and for stacking the work after sewing. Least common are those that assist the initial picking up of the parts to be sewn. In terms of their method of working, some are purely mechanical, some operate pneumatically, some are photo electric and some are electronic. Some are built into the machine such as a special motor some are a variation of a normal machine part such as a special presser foot, and some are completely separate added part.

Seam guides: are used for correct sewing in predetermined position or in a determined and proper distance form edge of fabric. It is also used for straight and curved sewing to increase the quality and productivity. Edge guides are used in over edge machine.

Folder is an attachment to a sewing machine for bending and folding the fabric previous to sewing. It is belong to the category of work aids (Additional devices that can be added to basic sewing machines) generally used in situations where fabric must be fold prior to sewing Can be used for folds ranging from simple to complex. Different types of folders available in different size and thickness. Thickness of the folder is selected depends on type of fabric.

1. Light folder $(0.15 \mathrm{~mm}$ to $0.25 \mathrm{~mm}$ thickness $)$ - silk, synthetic materials, poplin, shirting, bed sheet

2. Medium folder $(0.27 \mathrm{~mm}$ to $0.40 \mathrm{~mm}$ thickness $)$-single jersey knit,

3. Heavy folder $(0.45 \mathrm{~mm}$ to $1.5 \mathrm{~mm}$ thickness $)$-twill, corduroy, rib knit, interlock knit, denim

There are different types of folders available but they are divided into three main groups that help to fold the parts of garments, to attach the parts and to attach other materials with garments finally.

Criteria of Folders: It is one of the sewing machine spare parts which folds one or more materials into the desired configuration. Folders are constructed for specific applications, which may provide for the insertion of tapes, trim fabrics and elastic so on at the same time as the material is folded.it must need the skilled operator to sew the fabric by folding. Also the quality and productivity are other factors related to it. To increase the production and to ensure the quality of products, folder is used; It may be placed in the middle or in front of pressure foot

\subsection{Improvement of Quality by use of Work aids}

Productivity is the conceptual measurable analysis of how much we have produce and how much we spent to produce; in general it is the ratio between outputs to input. ${ }^{[5]}$ 
In garment production, many operations are simple and repetitive. Workers have limited skills and do the same tasks every day, While this practice makes workers experts in their particular tasks and improves productivity, it creates monotony; monotony and lack of variety can cause burden and fatigue and repetition of the same movements can result in muscle strain and general stress, attention wander, quality suffers and the worker needs to stop the machine and recover the result is low efficiency and negative work attitude. ${ }^{[6]}$

Global trend of garment industry majorly related to the intense laborious activities. A systematic synchronization of process and operational parameters are required to produce a one piece of complete set of product. By optimizing productivity industry can able to optimize the raw material and other resources like men, material, and machine, time, space, capital etc. ${ }^{[7]}$

Garment industries in developing countries are more focused on sourcing of raw material and minimizing delivery cost than labour productivity because of the availability of cheap labour. Due to this, labour productivity is lower in developing countries than in the developed ones. ${ }^{[8]}$

Traditionally operated garment industries are facing problems like: - low productivity, longer production lead time, high rework and rejection, poor line balancing, low flexibility of style changeover. ${ }^{[9]}$

The term handling is normally used to describe those elements that are not sewing and it is this handling along with that dealing with garment bundling where they exist, plus various aspects of machine attention and personal needs, that make up 80 per cent of the time spent working by most sewing machinists. ${ }^{[10]}$

A sewing machine works with 20 per cent time and the next 80 per cent times for fabrics handling Fabric handling means the folding, thread trimming, placing of fabrics under the needle, shifting of bundles before \& after sewing and so on(Post, , 2016).

A regular sewing operator will pick-up, align, feed, sew, trim and dispose whereas, in an automated work station the operator or helper will be needed majority of the times to pick up, in some cases position the fabric in and start the machine. The machine takes control of sewing, trimming, and in majority of the cases disposing also. By allowing the operator to be free for major part of the sewing cycles either the factory can use someone with very less skill or the operator can be used to operate multiple machines at the same time thus enabling them to reduce labor cost and also the consistent quality products and higher productivity is achieved by automation. ${ }^{[4]}$

\section{METHODOLOGY}

To do this research work, we have employed the following tools and procedures. Computer used for documentation such as Sewing machine helps to test work aids, auto cad software used to design work aids, illustrator, SSP software used to sample calculation, and stop watch helps to record time taken. Sewing machine: -There are different types of machine, such as lock Stitch Machine, Flat Lock Machine, Bar Tuck Machine, blind machine, button hole stitch machine, over lock Machine and etc. from those lock stitch machines has been selected for this experiment. Stop watch will be used in the host enterprise for time study. Data collection was consisting of surveys, sewing room observations and interviews with [host enterprise] supervisor, as well as sewing operators and quality checkers. Initially, a survey instrument to measure operators' attitudes and beliefs regarding professional roles and responsibilities will be administered to a broad spectrum of participants (ideally, n=). Subsequently, a purposeful sample where been identified to participate in the second round of data collection. A structured observation protocol will be developed to aid in field note collection and an interview protocol rooted in the literature were been developed to act as a guide for the semi-structured interviews.

This denotes all the stages and the processes involved in reaching the respondents. The first step in the selection of a sample is to consider sampling technique. In sampling design, characteristics of the population to be studied must be clearly indicated. In view of the information needed for the study, and the nature of the population which is not distributed randomly but clusters. The study would adopt quota and purposive sampling techniques. Quota sampling was employed to specify certain percentages to each legal business in the enterprises which would be done based on the number of people in each group. After allocating percentages to each group, purposive sampling was used to choose respondents who were thought to be relevant to the data needed. This was used primarily when there were limited numbers of people who have expertise in the area being study. With the purposive sampling not everybody can give accurate information so head or deputy of established institutions was interviewed.

\subsection{Results}

In sewing section sewing operation was constructing without work aids by trained and less trained operators. The product which produces by those operators is Habasha Kamiss having upper torso and lower torso and cultural wear, trouser and vest. For those product time taken to produce a product were conducted through the below tables. 
International Journal of Engineering Research And Advanced Technology, Vol.6, Issue 8, August-2020

Table 2: Garment sewing operational breakdown and time taken.

1st garment (Habasha kamiss)

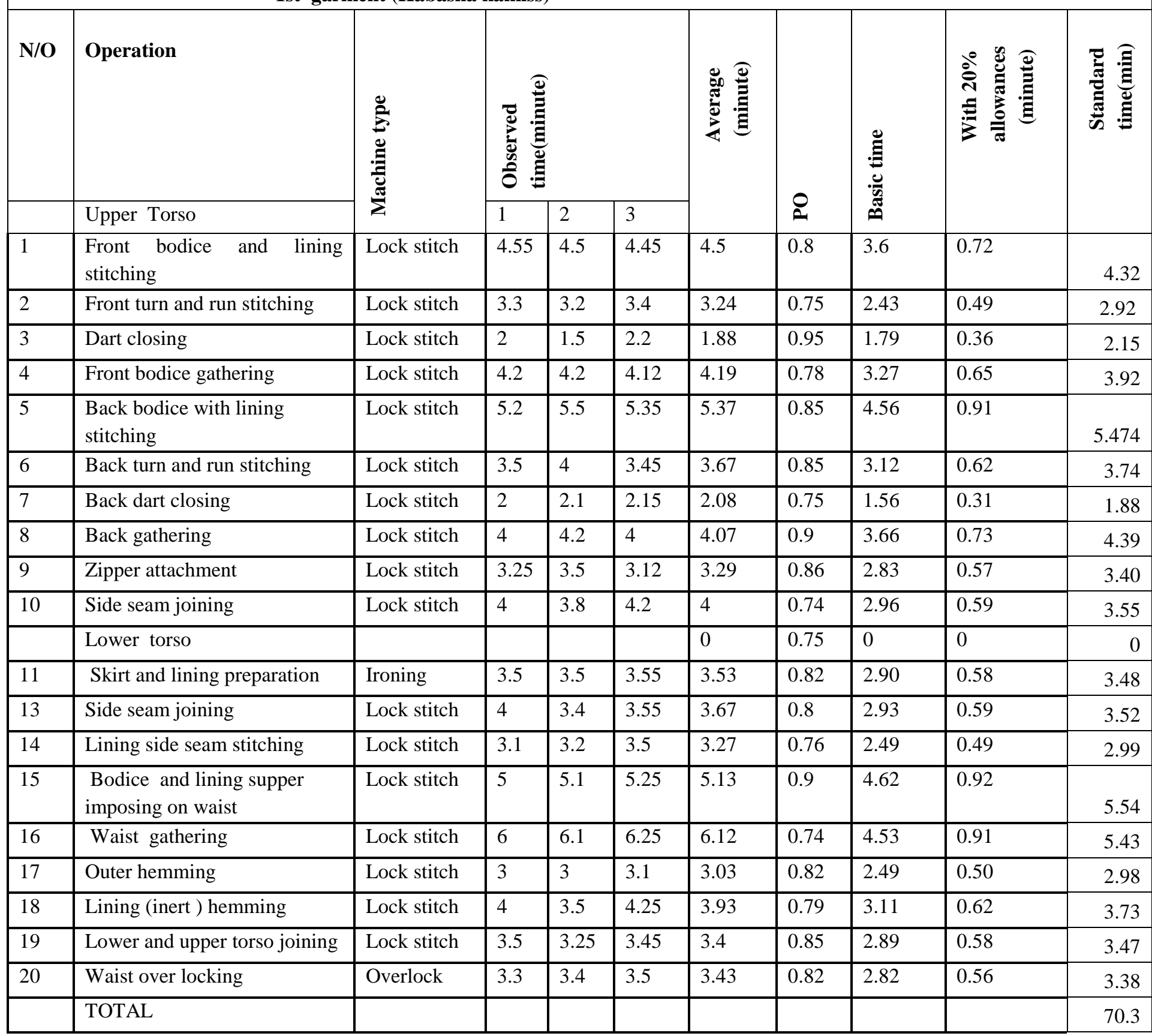


International Journal of Engineering Research And Advanced Technology, Vol.6, Issue 8, August-2020

Table 3: Experimental garment sewing operational breakdown and time taken variation

\begin{tabular}{|c|c|c|c|c|c|c|c|c|c|c|}
\hline & & & 2st G & armen & rouser & & & & & \\
\hline N/O & OPERATION NAME & & & & & & & & & \\
\hline & $\begin{array}{c}\text { Style Habasha Kamiss } \\
\text { Upper Torso }\end{array}$ & 苂 & & & 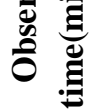 & $\sum_{4}^{\bar{d}}$ & 学 & 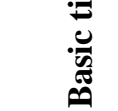 & สิ & 离 \\
\hline & & & 1 & 2 & 3 & & & & & \\
\hline 1 & Serging All body parts & Over lock & 6 & 6.21 & 7 & 6.4 & 0.8 & 5.12 & 1.02 & 6.1472 \\
\hline 2 & Serging small parts & Over lock & 3 & 3.1 & 3 & 3.03 & 0.75 & 2.28 & 0.45 & 2.73 \\
\hline 3 & Attach Facing to pocketing & Lock stitch & 1 & 1.15 & 1.5 & 1.22 & 0.78 & 0.95 & 0.19 & 1.1388 \\
\hline 4 & Pocket bag making & Lock stitch & 3 & 2.55 & 3.2 & 2.92 & 0.85 & 2.48 & 0.5 & 2.975 \\
\hline 5 & Side pocket bone & Lock stitch & 2.5 & 2.25 & 2.15 & 2.3 & 0.85 & 1.96 & 0.39 & 2.346 \\
\hline 6 & Pocket and pleat making & Lock stitch & 2.35 & 2.2 & 2 & 2.19 & 0.98 & 2.14 & 0.43 & 2.5676 \\
\hline 7 & Attach zipper to right fly & Lock stitch & 2 & 2.15 & 2.05 & 2.07 & 0.9 & 1.86 & 0.37 & 2.232 \\
\hline 8 & Attach left fly to body & Lock stitch & 2 & 2.1 & 2 & 2.03 & 0.86 & 1.75 & 0.35 & 2.0984 \\
\hline 9 & Crotch seam / Zipper finish & Lock stitch & 2.5 & 2.15 & 2.3 & 2.32 & 0.74 & 1.71 & 0.34 & 2.0572 \\
\hline 10 & $\mathbf{J}-$ Stitch & Lock stitch & 2 & 2.15 & 2.03 & 2.06 & 0.75 & 1.55 & 0.31 & 1.854 \\
\hline 11 & $\mathrm{~T} / \mathrm{S}$ crotch & Lock stitch & 2.25 & 2.3 & 2.5 & 2.35 & 0.82 & 1.93 & 0.39 & 2.3124 \\
\hline 12 & Attach Facing to pocketing & Lock stitch & 1 & 1.03 & 1.06 & 1.03 & 0.76 & 0.78 & 0.16 & 0.9394 \\
\hline 13 & Make a pocket welt & Lock stitch & 3 & 3.02 & 3.2 & 3.08 & 0.9 & 2.77 & 0.55 & 3.3192 \\
\hline 14 & welt / Tack at sides & Lock stitch & 4 & 4.25 & 4.2 & 4.15 & 0.74 & 3.07 & 0.61 & 3.6852 \\
\hline 15 & Press Pocket & Iron & 1.5 & 1.3 & 1.44 & 1.41 & 0.82 & 1.16 & 0.23 & 1.3907 \\
\hline 16 & Finish pocket bag & Lock stitch & 3 & 3.22 & 3.12 & 3.11 & 0.79 & 2.46 & 0.49 & 2.9514 \\
\hline 17 & Back rise & Lock stitch & 2 & 2.17 & 2.2 & 2.12 & 0.85 & 1.81 & 0.36 & 2.1658 \\
\hline 18 & Make loop & Lock stitch & 3 & 3.1 & 3.12 & 3.07 & 0.95 & 2.92 & 0.58 & 3.5036 \\
\hline 19 & Attach loop to waistband & Lock stitch & 4.1 & 4.08 & 4.02 & 4.06 & 0.85 & 3.46 & 0.69 & 4.148 \\
\hline 20 & attach griper & Lock stitch & 4.15 & 4.19 & 4.2 & 4.18 & 0.75 & 3.13 & 0.63 & 3.762 \\
\hline 21 & $\mathrm{~T} / \mathrm{S}$ on gripper & Lock stitch & 2.25 & 2.31 & 2 & 2.19 & 0.78 & 1.71 & 0.34 & 2.0467 \\
\hline 22 & Side seam & Lock stitch & 3.5 & 3.4 & 3.2 & 3.37 & 0.95 & 3.19 & 0.64 & 3.838 \\
\hline 23 & Inseam & Lock stitch & 3 & 3.2 & 3.1 & 3.1 & 0.95 & 2.95 & 0.59 & 3.534 \\
\hline 24 & Waistband attach & Lock stitch & 6 & 6.08 & 6.2 & 6.09 & 0.98 & 5.97 & 1.19 & 7.1658 \\
\hline 25 & Waistband finish & Iron & 3 & 2.55 & 3.2 & 2.92 & 0.85 & 2.47 & 0.5 & 2.975 \\
\hline 26 & Bottom hem & overlock & 2.2 & 2.1 & 2 & 2.1 & 0.75 & 1.57 & 0.32 & 1.89 \\
\hline 27 & decor making at leg & Lock stitch & 3 & 3.2 & 3.03 & 3.08 & 0.9 & 2.77 & 0.55 & 3.3228 \\
\hline 28 & $\begin{array}{l}\text { Eyelet button hole at } \\
\text { waistband }\end{array}$ & Lock stitch & 1 & 0.8 & 1.2 & 1 & 0.9 & 0.9 & 0.18 & 1.08 \\
\hline 29 & Finish loop attaching & Lock stitch & 3 & 2.56 & 3.1 & 2.89 & 0.85 & 2.45 & 0.49 & 2.9444 \\
\hline 30 & Bartach at pockets and fly & Lock stitch & 3 & 3 & 3.25 & 3.083 & 0.9 & 2.78 & 0.55 & 3.33 \\
\hline & Total time taken & & & & & & & 98.2 & & 85.312 \\
\hline
\end{tabular}


International Journal of Engineering Research And Advanced Technology, Vol.6, Issue 8, August-2020

Table 4: Experimental Habasha kamiss sewing operational breakdown and time taken variation with sewing work aids during garment production.

\begin{tabular}{|c|c|c|c|c|c|c|c|c|c|c|c|}
\hline \multicolumn{12}{|c|}{ 1st garment (habasha kamiss) } \\
\hline \multirow[t]{3}{*}{ N/o } & operation name & \multirow{3}{*}{ 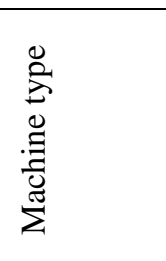 } & \multirow{3}{*}{ 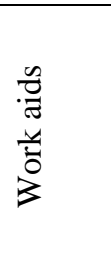 } & \multirow{2}{*}{\multicolumn{3}{|c|}{ 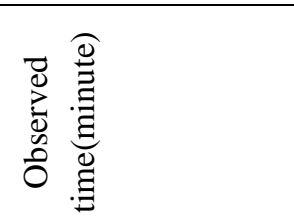 }} & \multirow{3}{*}{ 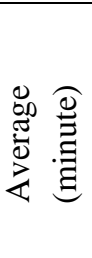 } & \multirow{3}{*}{$\ddot{D}$} & \multirow{3}{*}{ 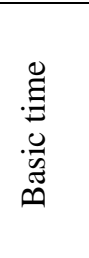 } & \multirow{3}{*}{ 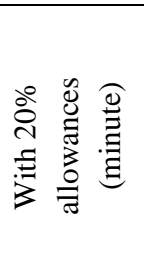 } & \multirow{3}{*}{ 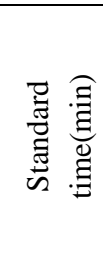 } \\
\hline & \multirow[t]{2}{*}{$\begin{array}{l}\text { Style habasha kamiss } \\
\text { upper torso }\end{array}$} & & & & & & & & & & \\
\hline & & & & 1 & 2 & 3 & & & & & \\
\hline 1 & $\begin{array}{l}\text { Front bodice and lining } \\
\text { stitching }\end{array}$ & Lock stich & Guide & 3 & 3.33 & $\begin{array}{c}3.1 \\
2\end{array}$ & 3.15 & 0.8 & 2.52 & 0.5 & 3.02 \\
\hline 2 & $\begin{array}{l}\text { Front turn and run } \\
\text { stitching }\end{array}$ & Lock stich & Guide & 3 & 3.5 & 4 & 3.5 & 0.75 & $\begin{array}{c}2.62 \\
5\end{array}$ & 0.53 & 3.15 \\
\hline 3 & Dart closing & Lock stich & & 2 & 3 & 2 & 2.33 & 0.95 & $\begin{array}{c}2.21 \\
7\end{array}$ & 0.44 & 2.66 \\
\hline 4 & Front bodice gathering & Lock stich & & 4 & 3 & 3.5 & 3.5 & 0.78 & 2.73 & 0.55 & 3.28 \\
\hline 5 & $\begin{array}{l}\text { Back bodice with lining } \\
\text { stitching }\end{array}$ & Lock stich & Guide & 3.5 & 3.15 & 3.2 & 3.28 & 0.85 & $\begin{array}{c}2.79 \\
1\end{array}$ & 0.56 & 3.35 \\
\hline 6 & $\begin{array}{l}\text { Back turn and run } \\
\text { stitching }\end{array}$ & Lock stich & Guide & 2 & 2.25 & 2 & 2.08 & 0.85 & $\begin{array}{c}1.77 \\
1\end{array}$ & 0.35 & 2.12 \\
\hline 7 & Back dart closing & Lock stich & & 2 & 2 & 2 & 2 & 0.75 & 1.5 & 0.3 & 1.8 \\
\hline 8 & Back gathering & Lock stich & & 4 & 3 & 4 & 3.67 & 0.9 & 3.3 & 0.66 & 3.96 \\
\hline 9 & Zipper attachment & Lock stich & & 3 & 3.5 & 3 & 3.17 & 0.86 & $\begin{array}{c}2.72 \\
3\end{array}$ & 0.54 & 3.27 \\
\hline 10 & $\begin{array}{l}\text { Upper side seam } \\
\text { joining }\end{array}$ & Lock stich & Guide & 2 & 2.3 & $\begin{array}{c}2.1 \\
4\end{array}$ & 2.15 & 0.74 & $\begin{array}{c}1.58 \\
9\end{array}$ & 0.32 & 1.91 \\
\hline & Lower torso & & & & & & 0 & 0.75 & 0 & 0 & 0 \\
\hline 11 & $\begin{array}{l}\text { skirt and lining } \\
\text { preparation }\end{array}$ & Ironing & & 3 & 3.75 & 2 & 2.92 & 0.82 & $\begin{array}{c}2.39 \\
2\end{array}$ & 0.48 & 2.87 \\
\hline 13 & Side seam joining & Lock stich & Guide & 2 & 1.5 & $\begin{array}{c}2.1 \\
3\end{array}$ & 1.88 & 0.8 & $\begin{array}{c}1.50 \\
1\end{array}$ & 0.3 & 1.8 \\
\hline 14 & $\begin{array}{l}\text { Lining side seam } \\
\text { stitching }\end{array}$ & Lock stich & Guide & 2.3 & 2.5 & $\begin{array}{c}2.2 \\
5\end{array}$ & 2.35 & 0.76 & $\begin{array}{c}1.78 \\
6\end{array}$ & 0.36 & 2.14 \\
\hline 15 & $\begin{array}{l}\text { lining supper imposing } \\
\text { on waist }\end{array}$ & Lock stich & Guide & $\begin{array}{c}3.1 \\
4\end{array}$ & 3.27 & $\begin{array}{c}3.1 \\
5\end{array}$ & 3.19 & 0.9 & $\begin{array}{c}2.86 \\
8\end{array}$ & 0.57 & 3.44 \\
\hline 16 & waist gathering & Lock stich & & 6 & 7 & 6.5 & 6.5 & 0.74 & 4.81 & 0.96 & 5.77 \\
\hline 17 & Outer hemming & Lock stich & Folder & $\begin{array}{c}2.1 \\
5\end{array}$ & 2.24 & $\begin{array}{c}2.3 \\
5\end{array}$ & 2.25 & 0.82 & $\begin{array}{c}1.84 \\
2\end{array}$ & 0.37 & 2.21 \\
\hline 18 & Lining (inert) hemming & Lock stich & Folder & $\begin{array}{c}2.7 \\
5\end{array}$ & 2.25 & $\begin{array}{c}2.3 \\
2\end{array}$ & 2.44 & 0.79 & $\begin{array}{c}1.92 \\
8\end{array}$ & 0.39 & 2.31 \\
\hline 19 & $\begin{array}{l}\text { Lower and upper torso } \\
\text { joining }\end{array}$ & Lock stich & & 3.5 & 3.25 & 4 & 3.58 & 0.85 & $\begin{array}{c}3.04 \\
6 \\
\end{array}$ & 0.61 & 3.65 \\
\hline 20 & Waist over locking & 3 tol & & $\begin{array}{c}3.7 \\
5\end{array}$ & 4 & 3.5 & 3.75 & 0.82 & $\begin{array}{c}3.07 \\
5\end{array}$ & 0.62 & 3.69 \\
\hline & Total & & & & & & & & & & 56.4 \\
\hline
\end{tabular}


International Journal of Engineering Research And Advanced Technology, Vol.6, Issue 8, August-2020

Table 5: Experimental Trouser sewing operational breakdown and time taken variation with sewing work aids during garment production

\begin{tabular}{|c|c|c|c|c|c|c|c|c|c|c|c|}
\hline \multicolumn{12}{|c|}{ 2nd Garment (Trouser) } \\
\hline \multirow[t]{3}{*}{ N/o } & operation name & \multirow{3}{*}{ 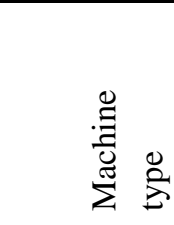 } & \multirow{3}{*}{ 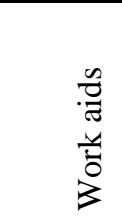 } & \multirow{2}{*}{\multicolumn{3}{|c|}{ 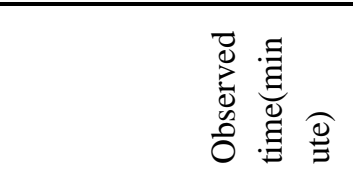 }} & \multirow{3}{*}{ 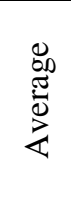 } & \multirow{3}{*}{ 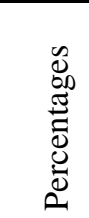 } & \multirow{3}{*}{ 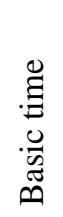 } & \multirow{3}{*}{ 究 } & \multirow{3}{*}{ 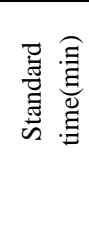 } \\
\hline & \multirow[t]{2}{*}{$\begin{array}{l}\text { Style Habasha kamiss } \\
\text { upper torso }\end{array}$} & & & & & & & & & & \\
\hline & & & & 1 & 2 & 3 & & & & & \\
\hline $\mathbf{1}$ & Serging all body parts & Over lock & & 6 & 6.21 & 7 & 6.4 & 0.8 & 5.1 & 1.02 & 6.147 \\
\hline 2 & Serging small parts & Over lock & & 3 & 3.1 & 3 & 3 & 0.75 & 2.3 & 0.45 & 2.73 \\
\hline 3 & facing to pocketing & Lock stich & & 1 & 1.15 & 1.5 & 1.2 & 0.78 & 0.9 & 0.19 & 1.139 \\
\hline 4 & Pocket bag making & Lock stich & Folder & 1 & 1.12 & 1.08 & 1.1 & 0.85 & 0.9 & 0.18 & 1.088 \\
\hline 5 & Side pocket bone & Lock stich & & 2.5 & 2.25 & 2.15 & 2.3 & 0.85 & 2 & 0.39 & 2.346 \\
\hline 6 & Pocket and pleat making & Lock stich & Folder & 0.8 & 0.6 & 1 & 0.8 & 0.98 & 0.8 & 0.16 & 0.941 \\
\hline 7 & zipper to right fly & Lock stich & & 2 & 2.15 & 2.05 & 2.1 & 0.9 & 1.9 & 0.37 & 2.232 \\
\hline 8 & left fly to body and & Lock stich & & 2 & 2.1 & 2 & 2 & 0.86 & 1.7 & 0.35 & 2.098 \\
\hline 9 & Crotch seam & Lock stich & & 2.5 & 2.15 & 2.3 & 2.3 & 0.74 & 1.7 & 0.34 & 2.057 \\
\hline 10 & $\mathrm{~J}-$ stitch & Lock stich & & 2 & 2.15 & 2.03 & 2.1 & 0.75 & 1.5 & 0.31 & 1.854 \\
\hline 11 & Top stitch of crotch & Lock stich & & 2.25 & 2.3 & 2.5 & 2.4 & 0.82 & 1.9 & 0.39 & 2.312 \\
\hline 12 & Attach facing to pocketing & Lock stich & & 1 & 1.03 & 1.06 & 1 & 0.76 & 0.8 & 0.16 & 0.939 \\
\hline 13 & Make a pocket welt & Lock stich & & 3 & 3.02 & 3.2 & 3.1 & 0.9 & 2.8 & 0.55 & 3.319 \\
\hline 14 & welt pocket tack & Lock stich & & 4 & 4.25 & 4.2 & 4.2 & 0.74 & 3.1 & 0.61 & 3.685 \\
\hline 15 & Press pocket & Iron & & 1.5 & 1.3 & 1.44 & 1.4 & 0.82 & 1.2 & 0.23 & 1.391 \\
\hline 16 & Finish pocket bag & Lock stich & & 3 & 3.22 & 3.12 & 3.1 & 0.79 & 2.5 & 0.49 & 2.951 \\
\hline 17 & Back rise & Lock stich & & 2 & 2.17 & 2.2 & 2.1 & 0.85 & 1.8 & 0.36 & 2.166 \\
\hline 18 & Make loop & Lock stich & Folder & 1.05 & 1.08 & 1 & 1 & 0.95 & 1 & 0.2 & 1.189 \\
\hline 19 & Attach loop to waistband & Lock stich & & 1.05 & 1 & 0.8 & 1 & 0.85 & 0.8 & 0.16 & 0.969 \\
\hline 20 & Attach griper & Lock stich & & 4.15 & 4.19 & 4.2 & 4.2 & 0.75 & 3.1 & 0.63 & 3.762 \\
\hline 21 & $\mathrm{~T} / \mathrm{s}$ on gripper & Lock stich & & 2.25 & 2.31 & 2 & 2.2 & 0.78 & 1.7 & 0.34 & 2.047 \\
\hline 22 & Side seam & Lock stich & Guide & 1 & 1.05 & 1.03 & 1 & 0.95 & 1 & 0.2 & 1.17 \\
\hline 23 & Inseam & Lock stich & Guide & 0.8 & 0.7 & 0.5 & 0.7 & 0.95 & 0.6 & 0.13 & 0.76 \\
\hline 24 & Waistband attach & Lock stich & Binder & 2.5 & 2.05 & 2.15 & 2.2 & 0.98 & 2.2 & 0.44 & 2.626 \\
\hline 25 & Waistband finish & Iron & & 1 & 1.05 & 1.08 & 1 & 0.85 & 0.9 & 0.18 & 1.064 \\
\hline 26 & Bottom hem & 3 tol & & 2.2 & 2.1 & 2 & 2.1 & 0.75 & 1.6 & 0.32 & 1.89 \\
\hline 27 & Decor making at leg & Lock stich & & 3 & 3.2 & 3.03 & 3.1 & 0.9 & 2.8 & 0.55 & 3.323 \\
\hline 28 & Eyelet at waistband & Lock stich & & 1 & 0.8 & 1.2 & 1 & 0.9 & 0.9 & 0.18 & 1.08 \\
\hline 29 & Finish loop attaching & Lock stich & & 3 & 2.56 & 3.1 & 2.9 & 0.85 & 2.5 & 0.49 & 2.944 \\
\hline 30 & Bar tack at pockets and fly & Lock stich & & 3 & 3 & 3.25 & 3.1 & 0.9 & 2.8 & 0.55 & 3.33 \\
\hline & Total time taken & & & & & & & & & & 65.55 \\
\hline
\end{tabular}

\section{Findings}

The small-scale enterprise founded in Bahir Dar are producing different garment through piece rate system and produce four to six products were been expected per operator per a day. Habasha Kamiss and cultural wear are popular in the enterprise which is seen through conduct in this research. The enterprise has many problems in sew room during sewing that reduces market of garment by increasing sewing faults that renders the garment quality such as hemming, sides seam and waist joining as shown below figure 


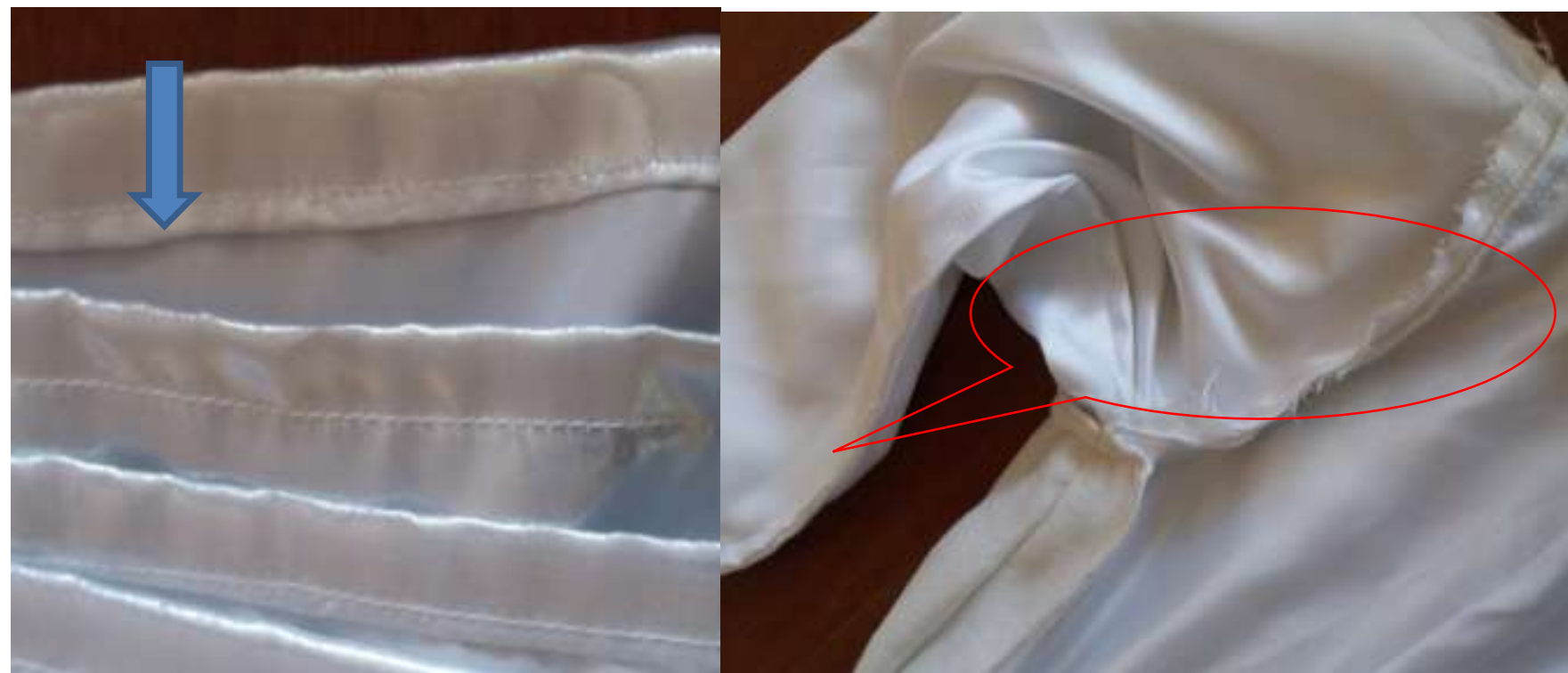

Figure 2. a. Figure 2.a. Bottom hemming defect
Figure 2.b.Armhole circumference defect

In sewing section sewing operation was constructing without work aids by trained and less trained operators. The products which produce by those operators are Habasha Kamiss having upper torso, lower torso, cultural wear, trouser and vest. For those product time taken to produce a product were conducted

Table 1: Variation of total time taken for without sewing work aid and with use of work aid in the sewing section.

\begin{tabular}{|l|c|l|}
\hline \multicolumn{1}{|c|}{ Total Time taken in minute } & \multicolumn{2}{|c|}{ style } \\
\cline { 2 - 3 } & Habasha Kamiss & Trouser \\
\hline Without use of sewing work aid (A) & 70.3 minute & 85.304 minutes \\
\hline With use of sewing work aid (B) & 56.3 minute & 65.55 minutes \\
\hline Variation of total time taken $(\mathrm{A}-\mathrm{B})=(\mathrm{C})$ & 14 minute & 19.8 minutes \\
\hline
\end{tabular}

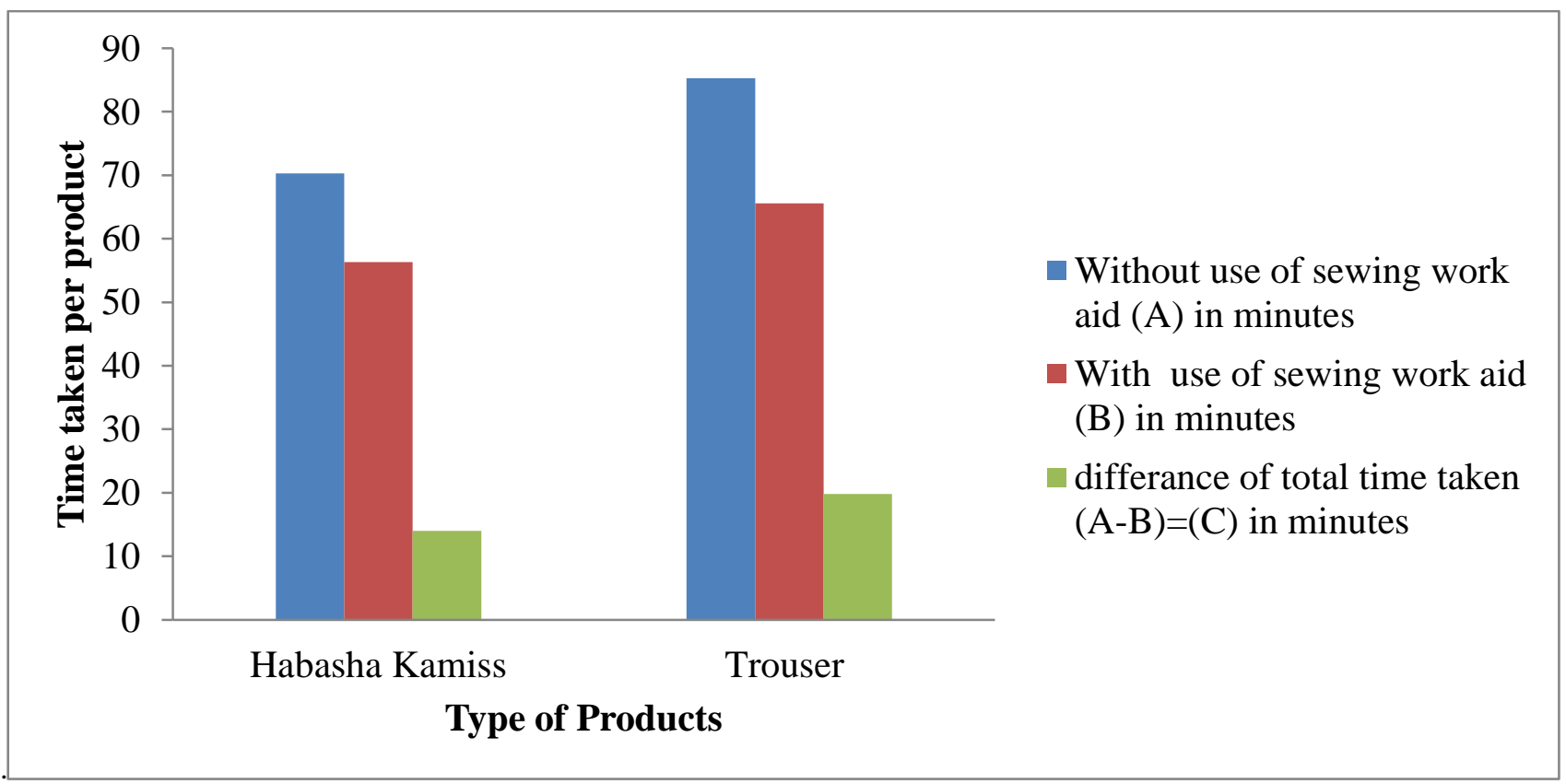

Figure 3: Comparison of time taken of various styles with and without work aids 
From the above diagram 1, it is seen that the total time taken to produce of a product (Habasha Kamiss) produced using sewing work aid and without work aid. As the result, the first garments (Habasha Kamiss) of time taken to produce lower than the same garment (Habasha Kamiss) produced without work aid. The matter is the same for 2nd garment (Trouser)

Table 2: Product with use of work aids and without work aids

\begin{tabular}{|c|c|c|c|c|c|c|}
\hline \multirow{2}{*}{$\begin{array}{l}\text { Observed } \\
\text { garment }\end{array}$} & \multirow{2}{*}{$\begin{array}{l}\text { No. of } \\
\text { operator }\end{array}$} & \multirow{2}{*}{$\begin{array}{l}\text { Working } \\
\text { hours }\end{array}$} & \multicolumn{2}{|c|}{ Calculated production } & \multirow[t]{2}{*}{ Difference } & \multirow[t]{2}{*}{ Remark } \\
\hline & & & $\begin{array}{l}\text { With sewing work } \\
\text { aids }\end{array}$ & $\begin{array}{l}\text { Without sewing work } \\
\text { aid }\end{array}$ & & \\
\hline $\begin{array}{l}\text { Habasha } \\
\text { kamiss }\end{array}$ & 9 & 8 Hours & $\begin{array}{l}62 \text { Habasha } \\
\text { Kamiss }\end{array}$ & 50 Habasha Kamiss & $\begin{array}{c}12 \text { Habasha } \\
\text { kamiss }\end{array}$ & \\
\hline Trouser & 9 & 8 Hours & 54 Trousers & 41 Trousers & 13 Trousers & \\
\hline
\end{tabular}

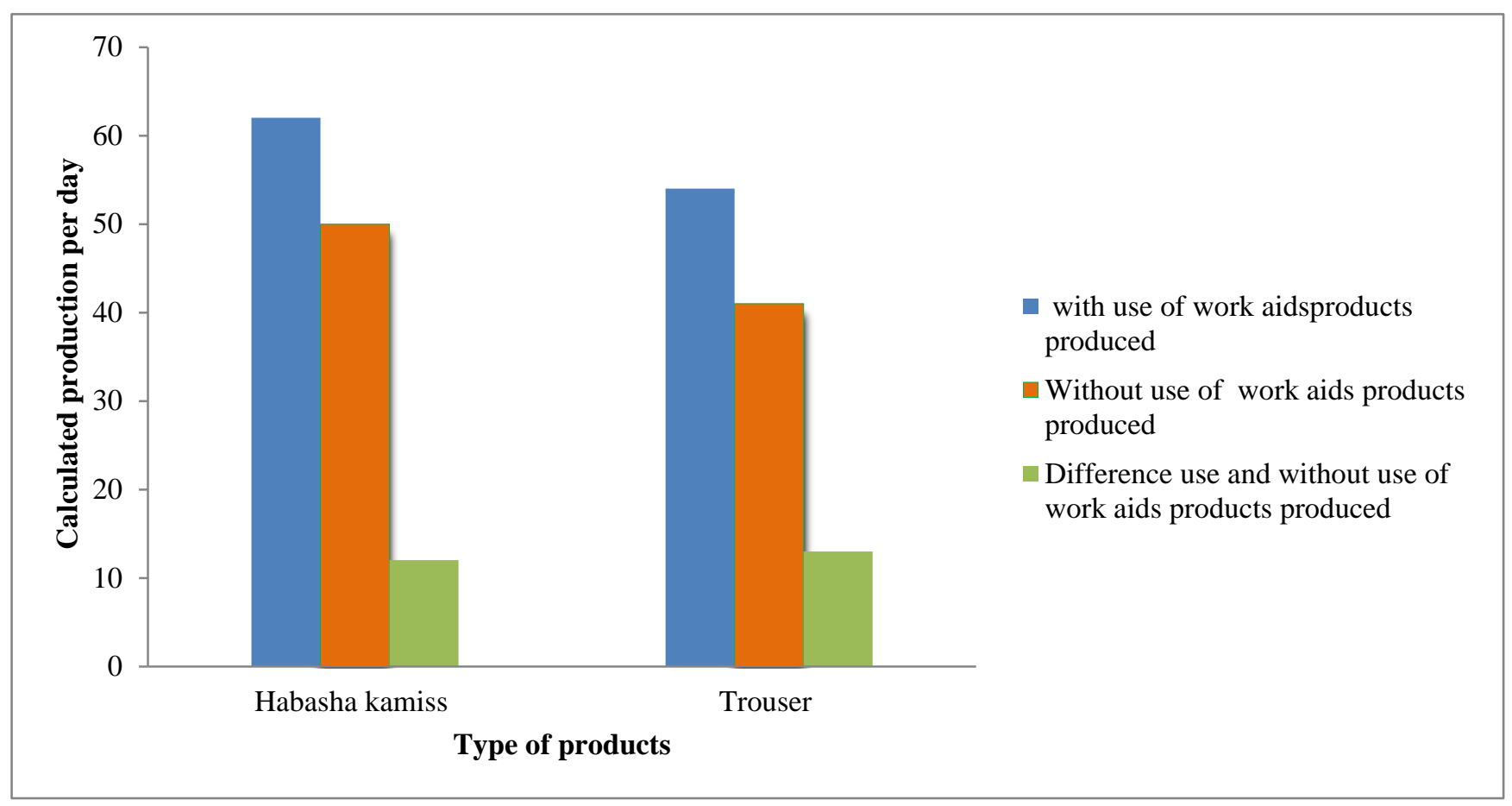

Figure 4: Comparison of production variation with and without work aids

From the above diagram, it seen that time taken of Habasha kamiss produced using work aid is lower than the same garment produced without using work aid. As a result the calculated production of the 1st Garment (Habasha kamiss) of 1st style is higher than the same Garment produced without using work aid. The matter the same for 2nd garment (Trouser). The difference daily production with and without work aid was 6 on average. Fast seen on sample prepared Work aids ensures a better quality and increase the productivity of a garment manufacturing process step.

\section{CONCLUSION}

Working aid is an important and essential part of any Garments Industry. Working Aid is one of the most effective sewing tools. In the domestic production of garments, the most time is wasted for the handling of fabric. To reduce this wastage in industrial production of garments work aids required. These work aids are not only used to reduce the handling time but also used to improve the quality of the garments. The extent of process control in maintaining the processing parameters at desired level can be reduced thereby maintaining quality $\&$ increasing productivity. For this purpose, this research project will be very helpful. Small Scale Enterprises should improve in terms of quantity and quality to maintain in market (competitiveness') and sustain the growth in order to change their status to medium level that the Enterprise use different productivity improvement techniques such as utilization of manpower, effective use of machines by use of some kinds of time saving devises that facilitate operators to perform their work effectively with less effort and short time. 


\section{REFERENCE}

[1] HEGDE, S. H. V. (2013). Assessment of Global Rice Production and Export Opportunity for Economic Development in Ethiopia, International Journal of Science and Research, Volume 2.

[2] PAUL, R. W. I. (2010). GROWTH DETERMINANTS OF WOMEN-OPERATED MICRO AND SMALL ENTERPRISES

IN ADDIS ABABA, Journal of Sustainable Development in Africa, Volume 12.

[3] DASANAYAKA, S. W. S. B. (2008). SMEs in Globalized World: A Brief Note on Basic Profiles of Pakistan's Small and Medium Scale Enterprises and Possible Research Directions Business Review Volume 3.

[4] TIMOTHY, P. R.. (2012). Automation and deskilling devices, INDIA

[5] POST, U. (2016). Work Aids-of-Sewing-Machines. Textile study centre

[6] HIBA, J. C. (1998). Improving Working Conditin and Productivity in the Garment Industry, International Labour Office.

[7] SUPRIT BORSE, V. S., V.S. SHIVANKAR (2016). Improving the Garment Productivity by Using New Designs of Folder, International Journal on Textile Engineering and Processes, Vol. 2.

[8] PANERU, N.(2011). Implementation of lean manufacturing tools in the garment manufacturing process focusing sewing section of Men's Shirt. Oulu University of Applied Sciences.

[9] B. NAVEEN*, D. T. R. B. (2012). Productivity Improvement in Manufacturing Industry Using Industrial Engineering Tools. Journal of Mechanical and Civil Engineering (IOSR-JMCE), PP 11-18.

[10] RAIHAN, S. (2016). Effect of Sewing Work Aid in Garments Production, International Journal of Textile Science, PP 49-59. 